\title{
Incidence of Central Serous Chorioretinopathy in Pre-Eclampsia Patient in Bundelkhand Region
}

\author{
Jitendra Kumar ${ }^{1}$, Amit Verma $^{2}$, Prachi $_{\text {Agarwal }}{ }^{3}$, Arun Pathak $^{4}$,Shweta Dwivedi ${ }^{5}$ \\ ${ }^{1}$ Associate Professor, Department Of Ophthalmology, Maharani Laxmi Bai Medical College, Jhansi, UP, India \\ ${ }^{2}$ Junior Resident, Department Of Ophthalmology, Maharani Laxmi Bai Medical College, \\ Jhansi, UP, India \\ ${ }^{3}$ Junior Resident, Department Of Obstetrics\& Gynaecology, Maharani Laxmi Bai \\ Medical College, Jhansi, UP, India \\ ${ }^{4}$ Junior Resident, Department Of Ophthalmology, Maharani Laxmi Bai \\ Medical College, Jhansi, UP, India \\ ${ }^{5}$ Junior Resident, Department Of Ophthalmology, Maharani Laxmi Bai \\ Medical College, Jhansi, UP, India
}

\begin{abstract}
:
Introduction: Central serous chorioretinopathy (CSCR) is a retinal disorder that primarily affects young (20- to 50-year-old) white men, although it is seen occasionally in older patients and females. CSC is characterized by avascular focal leakage through the retinal pigment epithelium (RPE), resulting in serous detachment of the neurosensory retina. The course of CSR is usually self-limiting and in most cases resolves spontaneously within a 3 month period, with visual acuity usually recovering to 20/30 or better.

Material and Methods: A single centre study was carried out on patients attending the outdoor andindoor patient department of obstetrics and gynecology and department of ophthalmology in Maharani Laxmi Bai Medical College, Jhansi.In this study total 290 pregnant women were taken who diagnosed preeclamsia in 1 year duration and 3 patients is confirmed CSCR by optical coherence tomography(OCT).

Conclusion: According to this study we found the incidence of CSCR in preeclampsia is $1.03 \%$ in Bundelkgand Region
\end{abstract}

Keywords: central serous chorioretinopathy, pre eclampsia, pregnancy

\section{Introduction}

Central serous chorioretinopathy (CSCR) is a serous detachment of the neurosensory retina, respectively retinal pigment epithelium (RPE) caused by a focal breakdown of the outer blood-retina barrier resulting in an accumulation of fluid between the photoreceptor outer segments and the RPE ${ }^{[1]}$.In its most common form, patients affected by CSC of recent onset complain of blurred vision with a relative central scotoma and metamorphopsia, possibly associated with dyschromatopsia, micropsia and a reduction in contrast sensitivity ${ }^{[2,3]}$

\section{Material And Method}

A total of 290 preeclampsia patient were included in this study conducted in the Department of Ophthalmology, Maharani Laxmi Bai Medical College, Jhansi, Uttar Pradesh, India over a period of 12 months from January 2016 to January 2017. The procedures followed were in accordance with the ethical standards committee on human experimentation (institutional or regional) and with the Helsinki Declaration of 1975, as revised in 2000. The necessary permission from the Ethical and Research Committee was obtained for the study.

In this study 290 pregnant females who had diagnosed as preeclampsia which was confirmed by blood pressure is $>140 / 90 \mathrm{mmhg}$ and urinary albumin is +1 or $>+1$. All patient underwent for routine fundus examination. On routine examination with direct ophthalmoscopy we found few patients have central serous chorioretinopathy which was confirmed by optical coherence tomography (OCT).

\begin{tabular}{|l|l|c|c|c|c|c|}
\hline \multicolumn{1}{|c|}{ TII. Table } \\
\begin{tabular}{|l|l|l|l|} 
Total number \\
of preeclampsia \\
(in 1 year)
\end{tabular} & $\begin{array}{l}\text { Mean Age } \\
\text { (in years) }\end{array}$ & $\begin{array}{c}\text { Mean Duration } \\
\text { of pregnancy } \\
\text { (in trimester) }\end{array}$ & $\begin{array}{c}\text { Mean } \\
\text { blood } \\
\text { pressure } \\
\text { (in mmhg) }\end{array}$ & $\begin{array}{c}\text { Mean } \\
\text { urinary } \\
\text { albumin } \\
\text { (dipstick } \\
\text { test) }\end{array}$ & $\begin{array}{c}\text { Total patients } \\
\text { of CSCR } \\
\text { (confirmed by } \\
\text { OCT) }\end{array}$ & $\begin{array}{c}\text { Incidence of } \\
\text { CSCR in } \\
\text { preeclampsia } \\
\text { patient(in \%) }\end{array}$ \\
\hline 290 & 26 & Third trimester & $170 / 96$ & $>+2$ & 03 & 1.03 \\
\hline
\end{tabular}




\section{Discussion}

Central serous chorioretinopathy (CSCR) is a localized retinal detachment of macular area. It is caused by a localized defect of the underlying retinal pigment epithelium (RPE) resulting in fluid of choroidal origin coming to subretinal space causing serous macular detachment. This condition affects young individuals between the ages of 20-50 years. The disease is seen predominantly in males as compared to females; the ratio is reported to be 10:1. Women with CSCR tend to be older, except in pregnancy. It is unilateral in $90 \%$ of patients. Increased incidence of CSCR has been observed in conditions like type A personality, pregnancy, and Cushing's syndrome. In these conditions, the increase in the level of endogenous cortisol is thought to be involved in the pathogenesis ${ }^{[4]}$. Other risk factors implicated in the pathogenesis include stress, steroids, hypertension, and SLE.

The presenting symptoms are unilateral blurring of vision (rarely bilateral), metamorphopsia, micropsia, mild dyschromatopsia, a relative positive scotoma, photopsia, occasional macropsia, and moderately reduced visual acuity ${ }^{[5]}$. Although more common in the third trimester, it may also occur during the first or second trimesters. Most CSCR heals spontaneously in 4-8 weeks postpartum, with recovery of visual acuity within 3 to 6 months. But RPE alterations, metamorphopsia, and central visual field changes may rarely persist with severe visual loss reported in 5\% of CSCR. Recurrences are known to occur in future pregnancies and $10 \%$ have three or more recurrences. Half of the recurrences occur within one year but may occur up to 10 years after the first episode ${ }^{[5]}$.

Ophthalmoscopy reveals a circumscribed round or oval area of retinal elevation in the macula area. Slitlamp biomicroscopy typically shows serous elevation of the macula. The diagnosis of CSCR is confirmed by OCT and fluorescein angiography, which demonstrates the site of RPE detachment and the site of leakage of serous fluid from the RPE into the subretinal space.

\section{Conclusion}

In this study we found the incidence of CSCR is $1.03 \%$ in preeclampsia patients in bundelkhand region.

\section{References}

[1]. Gelber GS, Schatz H (1987) Loss of vision due to central serous chorioretinopathy following psychological stress. Am J Psychiatry 144(1): 46-50.

[2]. Gass JD: Pathogenesis of disciform detachment of the neuroepithelium. Am J Ophthalmol 1967; 63(suppl):1-139.

[3]. Wang M, Munch IC, Hasler PW, Prunte C, Larsen M: Central serous chorioretinopathy. Acta Ophthalmol 2008; 86: 126-145.

[4]. Bouzas EA, Scott MH, Mastorakos G, Chrousos GP, Kaiser-Kupfer MI. Central serous chorioretinopathy in endogenous hypercortisolism. Arch Ophthalmol 1993; 111:1229-32.

[5]. D Hussain, JD Gass. Idiopathic central serous chorioretinopathy. (Current ophthalmology. 1998); 46(3): 131-137. 